\title{
Distribution and diet of four species of carcharhinid shark in the Hawaiian Islands: evidence for resource partitioning and competitive exclusion
}

\author{
Yannis P. Papastamatiou ${ }^{1, *}$, Bradley M. Wetherbee ${ }^{2}$, Christopher G. Lowe ${ }^{3}$, \\ Gerald L. Crow ${ }^{4}$ \\ ${ }^{1}$ Department of Zoology, Hawaii Institute of Marine Biology, University of Hawaii at Manoa, 46-007 Lilipuna Rd, Kaneohe, \\ Hawaii 96744, USA \\ ${ }^{2}$ Department of Biological Sciences, University of Rhode Island, Kingston, Rhode Island 02881, USA \\ ${ }^{3}$ Department of Biological Sciences, California State University Long Beach, Long Beach, California 90840, USA \\ ${ }^{4}$ Waikiki Aquarium, 2777 Kalakaua Ave, Honolulu, Hawaii 96815, USA
}

\begin{abstract}
Competition and predation are both important in structuring the distribution of marine organisms; however, little is known about how competition and predation influence the distribution of elasmobranch fishes. We used data collected from shark control programs conducted between 1967 and 1980, throughout the Hawaiian island chain, to examine the distribution and dietary overlap of the 4 most abundant carcharhinid sharks. Tiger sharks Galeorcerdo cuvier and Galapagos sharks Carcharhinus galapagensis were caught at all islands, but were more abundant in the northwestern Hawaiian Islands (NWHI) than in the main Hawaiian Islands (MHI). Gray reef sharks Carcharhinus amblyrhynchos and sandbar sharks Carcharhinus plumbeus showed an inverse relationship in distribution, with sandbar sharks abundant in the MHI, but virtually absent throughout the NWHI, and gray reef sharks only sporadically found throughout the MHI, but abundant in the NWHI. Dietary overlap was high between gray reef and sandbar sharks, and between sandbar and Galapagos sharks. Tiger sharks had low dietary overlap with all other species, except for large Galapagos sharks. The data analyzed in our study support the hypothesis that interspecific competition influences the distribution of carcharhinid sharks throughout the Hawaiian Archipelago.
\end{abstract}

KEY WORDS: Diet · Competition · Tiger shark · Galapagos shark · Gray reef shark · Sandbar shark

\section{INTRODUCTION}

Competition and predation are both fundamental components of the environment that influence community structure and the realized niche of individual organisms (Krebs 2001). Ecological theory predicts that resource partitioning on spatial, temporal, or trophic levels may increase tolerance of niche overlap and may reduce the pressure of competition between competing species. Although reduction of competition through resource partitioning between sympatric populations has been documented (e.g. Langeland et al. 1991), far less is known about the potential influence of competition on competitive exclusion and the formation of allopatric populations of closely related species that occupy similar niches.

A number of studies have investigated the influence of competition on competitive exclusion and resource partitioning in teleost fishes (e.g. Zaret \& Rand 1971, Hixon 1980). Results suggest that habitat partitioning may be related to high dietary overlap between competing species, or to interactive competition, where competing species have the same prey preference (e.g. Hixon 1980, Jansen et al. 2002). Although elasmobranchs play an important role in the marine environment (Cortés 1999, Lucas \& Stobo 2000, Heithaus 2004) 
and many species of elasmobranchs co-occur and occupy apparently similar roles as apex predators in marine ecosystems, little is known about resource partitioning and competitive exclusion among elasmobranchs. The large size of many elasmobranchs, their relatively low abundance, high mobility, and occurrence in a concealing medium contribute to the formidable task of experimental investigation of competition between species. One of the few sources of data for investigation of competition and resource partitioning among elasmobranchs is indirect evidence based on data on diet and spatial distribution among potentially competing species. The few studies that have attempted to investigate competition and resource partitioning between elasmobranchs have examined dietary and habitat overlap among sympatric species within small spatial scales (e.g. Cartamil et al. 2003, Bethea et al. 2004, White et al. 2004). Several studies have suggested that competition between elasmobranchs may actually alter or limit abundance of less competitive species (Ellis et al. 1996, Dulvy et al. 2000). Studies that address the effect of competition on resource partitioning and the distribution of elasmobranchs are lacking.

The Hawaiian archipelago spans a distance of $2500 \mathrm{~km}$ and is composed of several populated, highrelief islands (main Hawaiian Islands [windward], $\mathrm{MHI}$ ), and several older, unpopulated, low-relief islands (northwestern Hawaiian Islands [leeward], NWHI) (Fig. 1). Environmental conditions between the $\mathrm{MHI}$ and NWHI differ in several respects. Coral reef habitat in the NWHI is much more extensive, and this section of the archipelago includes several welldeveloped atolls. The MHI are generally characterized by fringing reefs, with occasional barrier reefs, and are also influenced by geographic weather patterns, resulting in elevated rainfall and freshwater runoff in comparison to the NWHI. Anthropogenic influences, such as pollution, habitat degradation, and fishing pressure, are also much greater in the MHI than in the NWHI.

The 4 most abundant sharks in the coastal waters surrounding the Hawaiian Islands are sandbar sharks Carcharhinus plumbeus, tiger sharks Galeorcerdo cuvier, Galapagos sharks Carcharhinus galapagensis, and gray reef sharks Carcharhinus amblyrhynchos (Wetherbee et al. 1994). In response to concerns over shark attacks on humans, large-scale shark fishing programs were conducted in Hawaii from 1959 to 1976 (see Wetherbee et al. 1994). During this period, $>4500$ sharks were caught within the MHI, providing information on distribution, reproduction, and diet for 15 species of sharks (Crow et al. 1996, Lowe et al. 1996, Wetherbee et al. 1996, 1997, McElroy et al. 2006). A large number of sharks (particularly tiger, gray reef, and Galapagos sharks) were also captured in fishing surveys conducted in the NWHI from 1978 to 1980 (DeCrosta et al. 1984). Preliminary examination of data collected during these programs indicated that these species had different distributional patterns that were in some ways contrary to conventional thought. For example, most sharks observed underwater by divers in the MHI were identified as gray reef sharks, although these sharks are not common in the MHI and have a sporadic distribution in comparison to the other most common species of sharks. The feeding ecology of these sharks also appeared to vary within and among species (Lowe et al. 1996, Wetherbee et al. 1996, 1997, McElroy et al. 2006). The data collected during these shark fishing programs, therefore, presented an unusual opportunity to examine a large quantity of data on diet and distribution of 4 species of sharks, to investigate competition

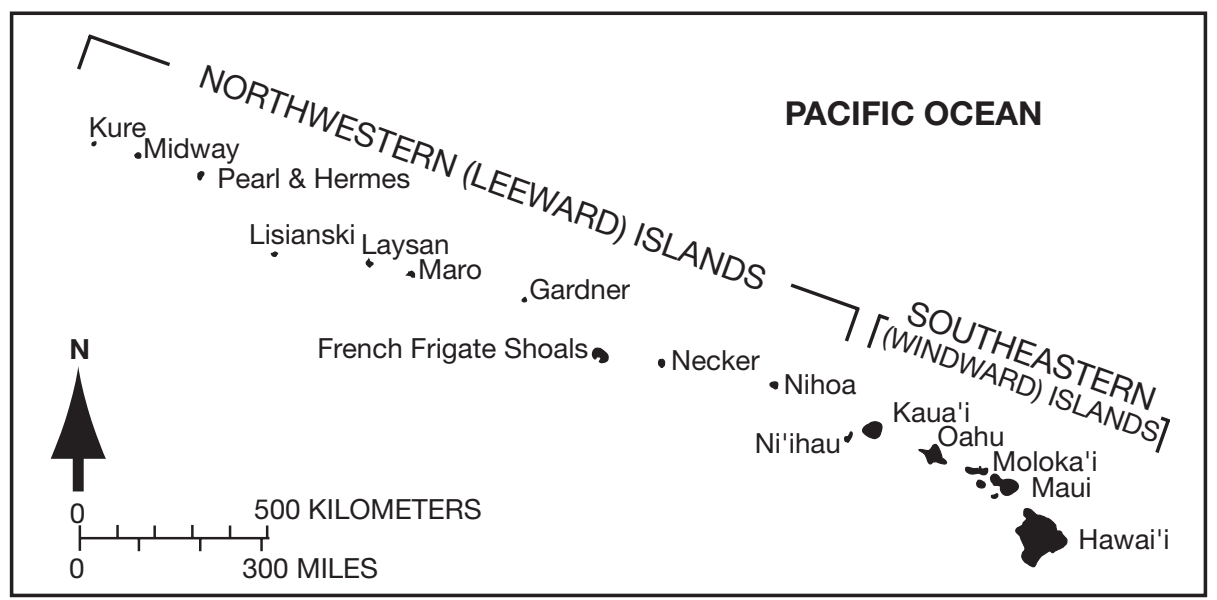

Fig. 1. Location of the main Hawaiian Islands (southeastern windward islands) and the northwestern Hawaiian Islands (leeward islands) 
and resource partitioning among these species. The objectives of our study were to quantify and compare the diets and the geographical and depth distributions of 4 common species of carcharhinid sharks in the Hawaiian Islands, with the overall goal of examining the available data for evidence of resource partitioning and/or competition.

\section{MATERIALS AND METHODS}

Data were taken from the original data sheets of the Hawaii Cooperative Shark Research and Control Program, which ran from June 1967 through June 1969, and from records collected during additional fishing conducted in the MHI between 1971 and 1976 (Wetherbee et al. 1994). During these programs, sharks were caught using standard bottom long-line gear, consisting of 3 sections of $800 \mathrm{~m}$ each with 24 hooks per section, baited primarily with skipjack tuna Katsuwonus pelamis. In general, lines were set in the late afternoon, parallel with the shore at an average depth of approximately $45 \mathrm{~m}$, but ranging to depths of $300 \mathrm{~m}$, and retrieved the next morning. Sharks (primarily smaller individuals) were also captured on light tackle long-lines (12 hooks, set between 18 and $118 \mathrm{~m}$ ) and hand-lines. Fishing was conducted around all of the main Hawaiian Islands, although the majority of trips consisted of multiple circuits around the island of Oahu (Fig. 1). Data from the NWHI were obtained from sharks captured by similar long-line fishing, handlines, and occasionally by spear fishing between 1978 and 1980 (see DeCrosta et al. 1984). Passive fishing techniques such as long-lining are known to bias diet analysis by targeting hungry individuals (Cortés 1997), and the $12 \mathrm{~h}$ soak times may increase the representation of less digestible prey items in stomachs. However, this comprehensive dataset included stomach contents from 1000s of sharks collected from a variety of species at a variety of depths, locations, and seasons, and therefore presumably reflects the general feeding habits of the species examined.

Each individual captured was identified to species and weighed and measured in terms of precaudal length (PCL) and total length (TL). Catch per unit effort (CPUE) for each shark species was expressed as the total number of sharks caught per 100 hooks. CPUE data were $\log (x+1)$ transformed, and linear regression analysis was used to quantify species pairwise interactions.

Depth of capture data was used to construct depthfrequency histograms for juveniles, adult male sharks, and adult female sharks of each species. Frequency histograms were constructed for $20 \mathrm{~m}$ increments in depth. A null model was used to determine if the degree of vertical spatial overlap observed between sharks was greater than expected by chance alone. The null model generates a large number of pseudocommunities by reshuffling the percent number of sharks caught at each depth, for each species of shark and its size range, and statistically compares the simulated overlap values with the observed overlap values (Connor \& Simberloff 1979). Essentially, the null model generates $\mathrm{p}$-values to determine if the observed overlap is statistically greater or less than that expected by chance alone. Significance was set at the $\mathrm{p}=0.05$ level. We used EcoSim (Ver. 7.0; Gotelli \& Entsminger 2001) to generate the null model and ran 1000 simulations using the RA3 algorithm (see Gotelli \& Entsminger 2001). The RA3 algorithm uses the Pianka index to calculate spatial overlap values, which range from 0 (no overlap) to 1 (complete overlap; Pianka 1973).

The stomach contents of sharks caught during the fishing programs were examined, and prey items were identified to the lowest possible taxonomic level. Because the original data sheets listed only prey types found in each stomach and did not include number of prey or gravimetric values, diets could be quantified only on the basis of percentage occurrence, i.e. the number of stomachs that contained a prey item as a percentage of all stomachs that contained prey.

Cumulative diversity curves were fit to the data to evaluate the adequacy of the sample size for precisely describing the diet. A diversity curve (or a cumulative prey curve) reaches an asymptote as the sample size becomes sufficient to describe the entire breadth of the diet (Ferry \& Cailliet 1996, Cortés 1997). We determined the number of new prey items in each additional stomach, after the order of the cumulative stomachs had been randomized 10 times to eliminate bias (Ferry \& Cailliet 1996, Cortés 1997). Prey diversity curves were calculated for gray reef, Galapagos, and tiger sharks. The curves have already been described for sandbar sharks caught during the fishing program (McElroy et al. 2006).

For comparison of diets, each species was subdivided into 3 size classes. The following size classifications were used: for tiger sharks: small $<200 \mathrm{~cm}$, medium $=200$ to $300 \mathrm{~cm}$, and large $>300 \mathrm{~cm}$ TL (Lowe et al. 1996); for Galapagos sharks: small < $150 \mathrm{~cm}$, medium = 151 to $200 \mathrm{~cm}$, and large > $201 \mathrm{~cm} \mathrm{TL}$ (Wetherbee et al. 1996); for gray reef sharks: small < $100 \mathrm{~cm}$, medium $=100$ to $150 \mathrm{~cm}$, and large $>150 \mathrm{~cm}$ TL (Wetherbee et al. 1997); and for sandbar sharks: small < $125 \mathrm{~cm}$, medium $=125$ to 150 , and large > $150 \mathrm{~cm}$ TL (McElroy et al. 2006). All size classifications were taken from earlier studies and were based on the size at which ontogenetic dietary shifts occur, as well as the size at reproductive maturity (see Lowe et al. 1996, Wetherbee et al. 1996, 1997). Prey diversity was 
calculated for all 4 species using the diversity index of Shannon-Wiener $\left(H^{\prime}\right)$ and Levin's standardized niche breadth $\left(B_{\mathrm{A}}\right)$ (Krebs 1999).

Diet was compared among size classes and among species with the simplified Morisita index $\left(C_{\mathrm{H}}\right)$, using Ecological Methodology Ver. 5.1 software (Krebs 1999). The simplified Morisita index is considered most appropriate for comparing resources that are expressed as proportions, and is also less sensitive to the number of dietary categories assigned during the analysis (Cortés 1997). Dietary overlap among species and size classes was evaluated on the basis of criteria suggested by Langton (1982): low (0 to 0.29 ), medium (0.3 to 0.59 ), and high (>0.6), and by using a null model to determine if the degree of dietary overlap observed between sharks was greater than that expected by chance alone (EcoSim Ver. 7.0; Gotelli \& Entsminger 2001). This time the resource states used in the model were percentage occurrence of a prey item in the diet of each shark species. We used the same model parameters set for the spatial overlap analysis described above. The null model was run for all species combined together, and then independently between species-size classes that showed high overlap. We did not include unidentified teleosts or indigestible items in any of the dietary analyses.

\section{RESULTS}

\section{Distribution}

Fishing effort was much greater in MHI (21134 hooks) than in NWHI (558 hooks); hence, CPUE data from the MHI are based on much larger sample sizes than data from the NWHI (Table 1). A total of 1088 sandbar, 550 tiger Galeorcerdo cuvier, 367 gray reef $C$. amblyrhynchos, and 304 Galapagos sharks C. galapagenis were captured. Catch data illustrate characteristic patterns of distribution for each of the 4 species within the entire Hawaiian Island chain (Table 1, Fig. 2). Both Galapagos sharks and tiger sharks were captured throughout both the MHI and the NWHI, although CPUE for both species was higher in the NWHI. With the exception of Niihau (3.4), CPUE of Galapagos sharks in the MHI was low (0.92). Although the number of individuals captured at some locations in the NWHI was low, the highest CPUE values for
Galapagos sharks were observed at Maro Reef (CPUE = 36.2, 29 sharks caught), Midway Atoll $(\mathrm{CPUE}=16.5,13$ sharks $)$, and Necker Island $(\mathrm{CPUE}=$ 25.0, 4 sharks) (Table 1). A similar trend was observed for tiger sharks, which had low CPUE at most locations in the MHI (1.4), with highest values recorded for Kaho'olawe (6.5). The highest CPUE for tiger sharks in the NWHI was recorded at Necker $($ CPUE $=18.8$, 3 sharks) and Midway (CPUE $=10.1,8$ sharks).

Few gray reef sharks were caught at most locations in the MHI. Although >100 gray reef sharks were caught in the MHI, nearly $80 \%$ of these were caught at Niihau and Molokini. High CPUE values were also recorded at Kaula Rock, although fishing was limited at this location. Not a single gray reef shark was captured on nearly 12000 hooks set off Oahu. Gray reef sharks were among the most abundant species in the NWHI, with highest CPUE at Necker and French Frigate Shoals (FFS). Sandbar sharks dominated catches within the $\mathrm{MHI}$; this species accounted for nearly $75 \%$ of the sharks caught off the islands of Hawaii, Maui, and Oahu, where most of the fishing was conducted (Fig. 2). Sandbar sharks were captured in large numbers throughout the MHI, and CPUE was relatively constant between the island of Hawaii (the southernmost $\mathrm{MHI}$ ) and Niihau (the northernmost MHI). Contrary to the MHI, sandbar sharks were uncommon in the NWHI. Only 2 of the 128 (1.6\%) sharks caught in NWHI fishing were identified as sandbar sharks; both individuals were caught at FFS. Analysis of CPUE data revealed significant relationships between species in several comparisons (Fig. 3). Significant negative relationships existed between 
A) $\mathrm{MHI}$
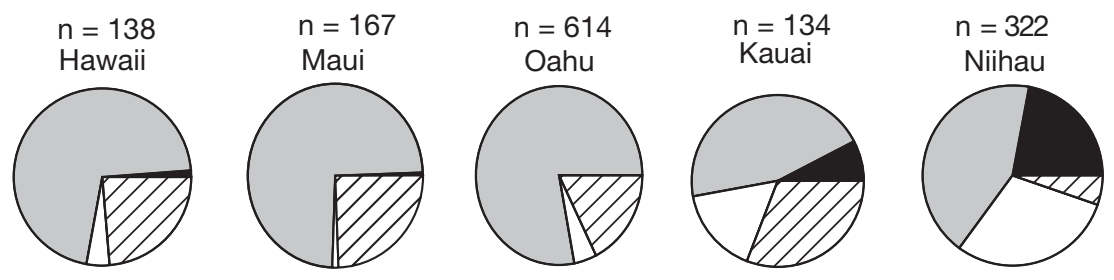

B) NWHI
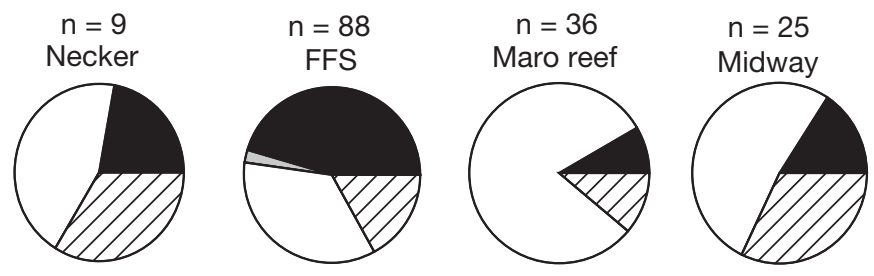

Fig. 2. Carcharhinus plumbeus, C. galapagensis, C. amblyrhynchos, Galeorcerdo cuvier. Relative contribution $(\%)$ of 4 species of shark to the overall species composition in (A) the main Hawaiian Islands (MHI) and (B) northwestern Hawaiian Islands (NWHI) (gray: sandbar shark; white: Galapagos shark; black: gray reef shark; striped: tiger shark; FFS: French Frigate Shoals). Number above each pie chart is the total number of sharks caught at each location

$\log (x+1)$ transformed CPUE of gray reef (GR) and sandbar (SB) sharks $\left(\mathrm{r}^{2}=0.42, F=7.37, \mathrm{p}=0.02\right)$, between tiger $(\mathrm{T})$ and sandbar sharks $\left(\mathrm{r}^{2}=0.34, F=\right.$ 5.22, $\mathrm{p}=0.045)$, and between sandbar and Galapagos (G) sharks $\left(\mathrm{r}^{2}=0.41, F=6.87, \mathrm{p}=0.03\right)$. A significant positive relationship was found between tiger and Galapagos sharks $\left(\mathrm{r}^{2}=0.59, F=14.5, \mathrm{p}=0.003\right)$. No significant relationship existed between the CPUE of gray reef and tiger sharks $(F=0.83, \mathrm{p}=0.38)$ and gray reef and Galapagos sharks $(F=3.9, \mathrm{p}=0.08)$.

The general trend observed for relative abundance of these 4 species was decreasing abundance of sandbar sharks and increasing abundance of gray reef sharks moving from south to north within the archipelago (Fig. 2). The dominant species in the MHI was the sandbar shark, whereas this species was essentially absent in the NWHI, where Galapagos sharks were the most common species captured. Maui and the northernmost MHI (Kauai and Niihau) represent the few areas where both sandbar and gray reef sharks were caught. Tiger and Galapagos sharks were captured throughout both the MHI and the NWHI, although CPUE values varied somewhat with location.

Because consecutive fishing circuits were conducted around Oahu from 1967 to 1969 , catch composition could be analyzed by season and compared over the 2 yr period (Fig. 4). The CPUE of tiger sharks caught from the winter of 1967 until the winter of 1969
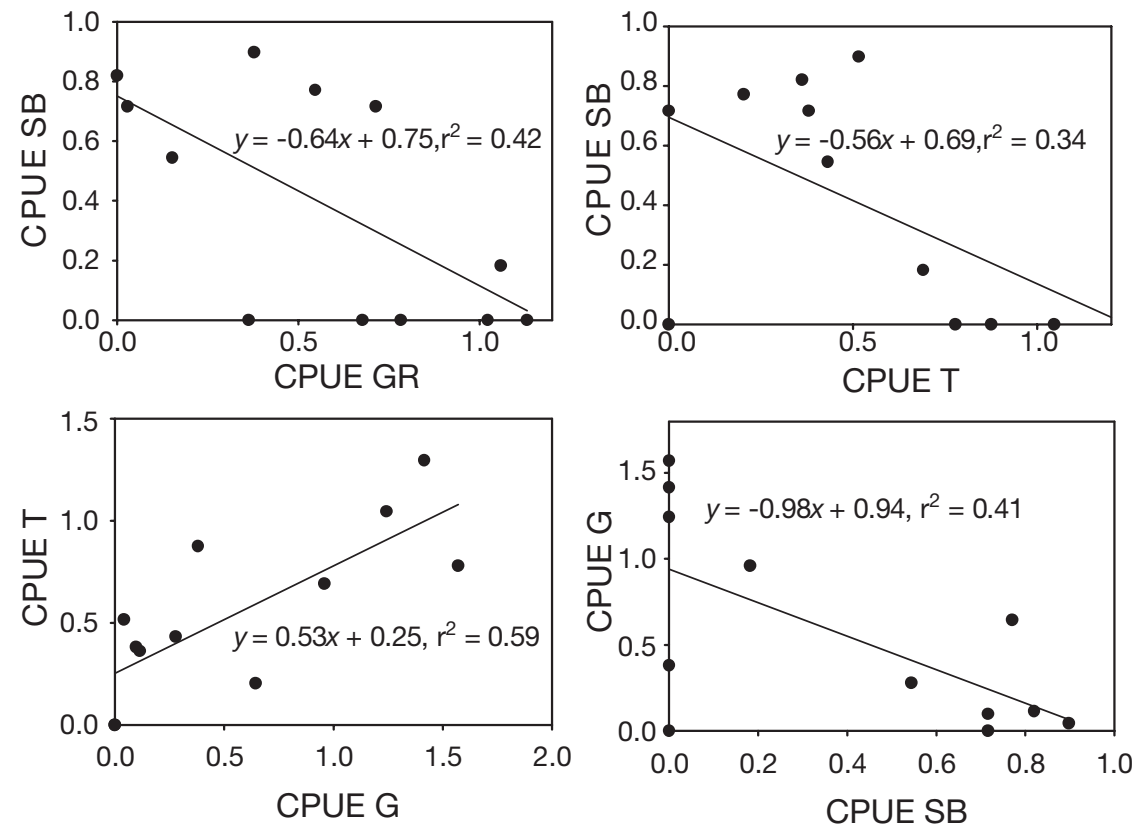

Fig. 3. Carcharhinus plumbeus, C. galapagensis, C. amblyrhynchos, Galeorcerdo cuvier. Regression analysis of catch per unit effort (CPUE, number of sharks per 100 hooks) between 4 species of shark in Hawaiian waters (GR: gray reef shark; T: tiger shark; G: Galapagos shark; SB: sandbar shark). All CPUE data are $\log (x+1)$ transformed. Note different scales 
for tiger sharks ranged between 18 and $370 \mathrm{~m}$, with no apparent segregation by depth (females: $44.7 \pm 32.1 \mathrm{~m}$, $\mathrm{n}=243$; males: $46.3 \pm 23.8 \mathrm{~m}, \mathrm{n}=215$; juveniles: $37.3 \pm 9.3 \mathrm{~m}, \mathrm{n}=37$ [mean $\pm \mathrm{SD}$ in all cases]; Fig. 5A).

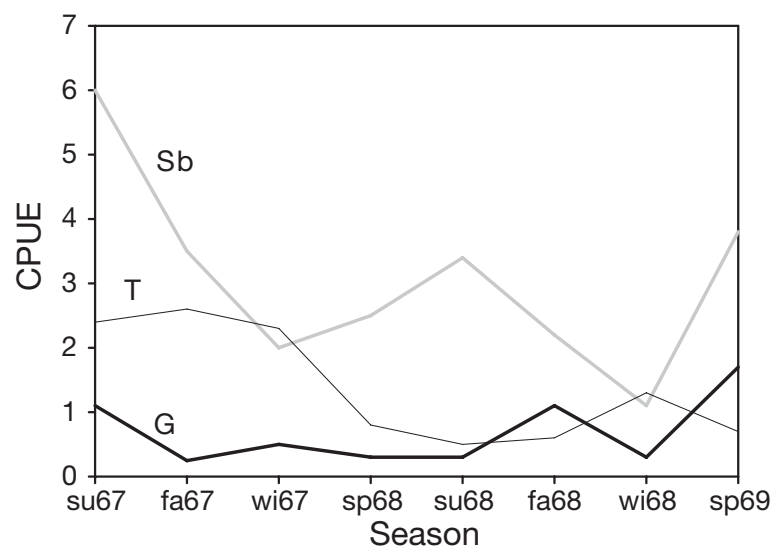

Fig. 4. Carcharhinus plumbeus, C. galapagensis, Galeocerdo cuvier. Changes in CPUE of sharks during successive fishing circuits around Oahu, from 1967 to 1969 (su: summer; fa: fall; wi: winter; sp: spring; Sb: sandbar shark; G: Galapagos shark; T: tiger shark). Data for sandbar and tiger sharks were taken from Wetherbee et al. (1994)
Between 87 and $97 \%$ of female, male, and juvenile tiger sharks were caught shallower than $60 \mathrm{~m}$. Sandbar sharks were caught at depths between 15 and $278 \mathrm{~m}$, and average depth of capture for mature females 46.1 $\pm 23.0 \mathrm{~m}(\mathrm{n}=373)$ was shallower than for mature males $71.7 \pm 43.2 \mathrm{~m}(\mathrm{n}=216)$. Only $15 \%$ of mature females were captured at depths $>90 \mathrm{~m}$, compared with $40 \%$ of mature males. Juvenile sandbar sharks were, on average, captured at intermediate depths (mean depth: $63.5 \pm 22.3 \mathrm{~m}, \mathrm{n}=74)$, and $67 \%$ were caught at depths >90 m (Fig. 5B; also see McElroy et al. 2006). Galapagos sharks were caught between 0 and $286 \mathrm{~m}$, with average depth of capture for females $(34.2 \pm 12.5 \mathrm{~m})$ shallower than that of males $(60.2 \pm 59.8 \mathrm{~m})$ and of juveniles $(45.1 \pm 23.3 \mathrm{~m}$ ) (Fig. 5C; also see Wetherbee et al. 1996). Gray reef sharks were caught between 1 and $106 \mathrm{~m}$, with females caught at an average depth of $22.2 \pm 15.8 \mathrm{~m}$, males at $36.2 \pm 20.0 \mathrm{~m}$, and juveniles at $37.5 \pm 12.8 \mathrm{~m}$ (Fig. 5D; also see Wetherbee et al. 1997).

However, the Pianka pairwise comparisons indicated a high degree of overlap between sharks in their depths of capture (Table 2). The mean spatial overlap for all sharks combined (0.80) was much greater than that expected by chance alone (simulated mean $=0.16$, $\mathrm{p}=0$ ). The observed variance (0.059) was not different
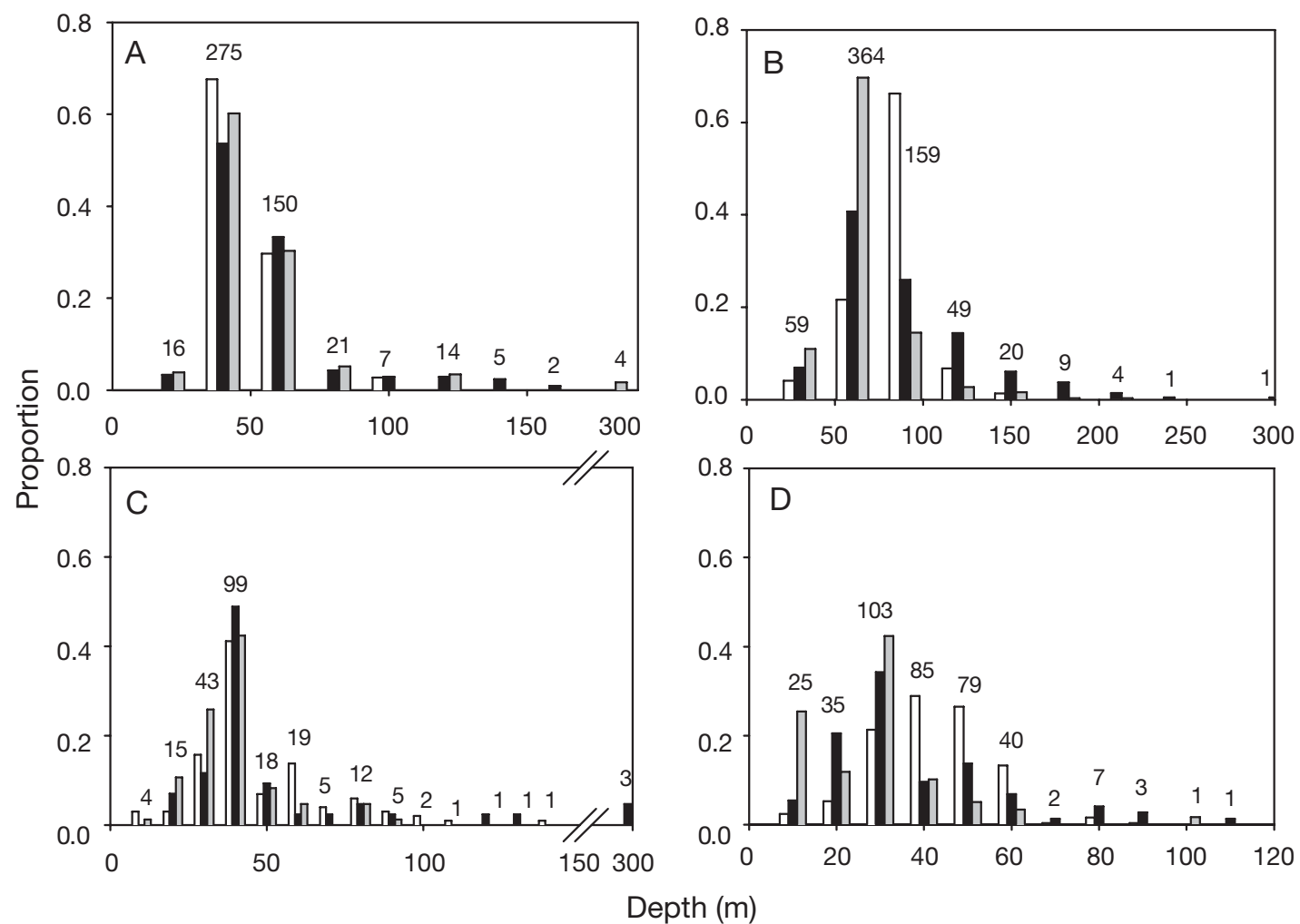

Fig. 5. Carcharhinus plumbeus, C. galapagensis, C. amblyrhynchos, Galeorcerdo cuvier. Depth of capture data for shark species caught in Hawaiian waters: (A) tiger shark, (B) sandbar shark, (C) Galapagos shark, and (D) gray reef shark. White bars: juveniles; black: mature males; gray: mature females. Numbers above bars indicate number of sharks caught 
Table 2. Carcharhinus plumbeus, C. galapagensis, C. amblyrhynchos, Galeorcerdo cuvier. Pianka overlap indices for depth of capture of sharks caught during fishing programs from 1967 to 1980 (JT: juvenile tiger; MT: male tiger; FT: female tiger; JG: juvenile Galapagos; MG: male Galapagos; FG: female Galapagos; JGR: juvenile gray reef; MGR: male gray reef; FGR: female gray reef; JSB: juvenile sandbar; MSB: male sandbar; FSB: female sandbar). Numbers in bold represent high overlap (>0.6). Significant overlap in the depth of capture existed between sharks $(p=0)$

MT $\quad$ FT JG $\quad$ MG $\quad$ FG $\quad$ JGR MGR FGR JSB MSB FSB

$\begin{array}{llllllllllll}\text { JT } & 0.98 & 0.99 & 0.98 & 0.96 & 0.96 & 0.96 & 0.88 & 0.79 & 0.20 & 0.81 & 0.98\end{array}$

$\begin{array}{llllllllllll}\mathrm{MT} & 0.99 & 0.97 & 0.93 & 0.93 & 0.99 & 0.90 & 0.78 & 0.29 & 0.85 & 0.98\end{array}$

FT

$\begin{array}{llllllllll}0.98 & 0.96 & 0.95 & 0.98 & 0.91 & 0.81 & 0.28 & 0.85 & 0.98\end{array}$

JG

MG

$\begin{array}{llllllll}0.98 & 0.98 & 0.94 & 0.91 & 0.83 & 0.34 & 0.88 & 1.0\end{array}$

$\begin{array}{lllllll}0.99 & 0.88 & 0.90 & 0.87 & 0.27 & 0.83 & 0.97\end{array}$

$\begin{array}{lllllll}0.89 & 0.92 & 0.90 & 0.22 & 0.79 & 0.96\end{array}$

$\begin{array}{llllll}0.90 & 0.78 & 0.26 & 0.80 & 0.94\end{array}$

JGR

$\begin{array}{llll}0.83 & 0.30 & 0.77 & 0.88\end{array}$

MGR

$\begin{array}{lll}0.16 & 0.63 & 0.79\end{array}$

FGR

0.670 .35

MSB

0.89

from that expected by chance alone (mean simulated variance $=0.045, p=0.86$ ), suggesting little variation in the Pianka index between species pairwise comparisons. The only group that showed low overlap in the depth of capture with other sharks was juvenile sandbar sharks (no significant overlap with male sandbar $[p=0.07]$ or with female sandbar sharks $[p=0.11]$ ). There was significant overlap between female gray reef and sandbar sharks ( $p=0.017)$ and between male gray reef and sandbar sharks $(p=0.008)$. Significant overlap existed between all other species size ranges $(\mathrm{p}=0$ to 0.006$)$.

\section{Diet and dietary overlap}

Table 3 lists prey items (expressed on the basis of percent occurrence) found in the stomachs of the 4 species of sharks and shows the dietary categories used in analyses (all size categories combined). The full dietary analysis for each size range of the 4 species can be found in Lowe et al. (1996), Wetherbee et al. (1996, 1997), and McElroy et al. (2006). Examination of broad taxonomic prey groups illustrates the variation in diet among these 4 species of sharks (Fig. 6). Gray reef sharks were highly piscivorous, with cephalopods and crustaceans accounting for the remainder of stomach contents. The diet of sandbar sharks was most similar to that of gray reef sharks, with a high occurrence of teleosts, followed by cephalopods, but sandbar sharks consumed more crustaceans than did gray reef sharks and some also consumed elasmobranchs and
Table 3. Carcharhinus plumbeus, C. galapagensis, C. amblyrhynchos, Galeorcerdo cuvier. Frequency of occurrence of prey items in the diet of 4 species of shark, taken from Hawaiian waters. Data are for all size ranges combined for each species of shark. Sharks were caught in the main and northwestern Hawaiian Islands from 1967 to 1980

\begin{tabular}{|c|c|c|c|c|}
\hline & Gray reef & Sandbar & Galapagos & Tiger \\
\hline $\begin{array}{l}\text { No. of stomachs } \\
\text { with food }\end{array}$ & 61 & 269 & 96 & 217 \\
\hline Molluscs & 29.5 & 26.5 & 30.2 & 13.4 \\
\hline Unid. cephalopod & 6.6 & 5.2 & 11.5 & 6.5 \\
\hline Octopus & 18.0 & 17.9 & 12.5 & 5.5 \\
\hline Squid & 4.9 & 4.1 & 6.3 & 1.4 \\
\hline Gastropod & 0 & 0.4 & 0 & 0 \\
\hline Crustaceans & 4.8 & 18.7 & 7.3 & 31.3 \\
\hline Unid. lobster & 0 & 0 & 1.0 & 11.1 \\
\hline Slipper lobster & 0 & 0 & 0 & 10.6 \\
\hline Spiny lobster & 1.6 & 1.9 & 3.1 & 6.5 \\
\hline Crab & 0 & 3.4 & 2.1 & 2.8 \\
\hline Shrimp & 1.6 & 1.9 & 2.1 & 0 \\
\hline Stomatopod & 0 & 5.2 & 0 & 0 \\
\hline Isopod & 0 & 0.4 & 0 & 0 \\
\hline Teleosts & 85.2 & 70.5 & 67.7 & 60.4 \\
\hline Tetradontidae & 0 & 0.4 & 0 & 9.2 \\
\hline Diodontidae & 0 & 1.9 & 7.3 & 25.8 \\
\hline Fistularidae & 0 & 0.7 & 0 & 1.8 \\
\hline Aulostomidae & 0 & 0.7 & 0 & 1.8 \\
\hline Carangidae & 0 & 1.9 & 6.3 & 2.3 \\
\hline Balistidae & 0 & 0.4 & 1.0 & 0.9 \\
\hline Congridae & 0 & 0.7 & 0 & 1.4 \\
\hline Sphyraenidae & 0 & 0.4 & 0 & 0.9 \\
\hline Mullidae & 0 & 1.5 & 0 & 0.5 \\
\hline Scaridae & 1.6 & 2.2 & 3.1 & 0.9 \\
\hline Coryphaenidae & 0 & 0 & 0 & 0.5 \\
\hline Labridae & 0 & 3.4 & 0 & 0.5 \\
\hline Pleuronectidae & 0 & 0 & 0 & 0.5 \\
\hline Belonidae & 0 & 0.4 & 1.0 & 0.5 \\
\hline Pomacentridae & 1.6 & 0 & 1.0 & 0.5 \\
\hline Monacanthidae & 3.3 & 1.1 & 4.2 & 0.5 \\
\hline Acanthuridae & 3.3 & 1.9 & 4.2 & 0.9 \\
\hline Scombridae & 0 & 0.4 & 4.2 & 2.3 \\
\hline Istiophoridae & 0 & 0 & 0 & 1.4 \\
\hline Ostraciidae & 0 & 0.4 & 0 & 0.5 \\
\hline Clupeidae & 0 & 0 & 1.0 & 0 \\
\hline Synodontidae & 0 & 0.4 & 1.0 & 0 \\
\hline Holocentridae & 4.9 & 1.1 & 2.1 & 0 \\
\hline Priacanthidae & 0 & 0.7 & 1.0 & 0 \\
\hline Lethrinidae & 0 & 0 & 1.0 & 0 \\
\hline Serranidae & 0 & 0 & 1.0 & 0 \\
\hline Scorpaenidae & 1.6 & 0.7 & 0 & 0 \\
\hline Chaetodontidae & 1.6 & 0.7 & 0 & 0 \\
\hline Zanclidae & 1.6 & 0.4 & 0 & 0 \\
\hline Bothidae & 0 & 0.7 & 0 & 0 \\
\hline Callionymidae & 0 & 0.4 & 0 & 0 \\
\hline Exocoetidae & 0 & 0.7 & 0 & 0 \\
\hline Lutjanidae & 0 & 0.7 & 0 & 0 \\
\hline Triglidae & 0 & 0.4 & 0 & 0 \\
\hline Elasmobranchs & 0 & 2.6 & 13.5 & 29.5 \\
\hline Sharks & 0 & 1.5 & 10.4 & 25.8 \\
\hline Rays & 0 & 0.7 & 3.1 & 3.7 \\
\hline Ophiurids & 0 & 0.4 & 0 & 0 \\
\hline Reptiles & 0 & 0 & 0 & 10.6 \\
\hline Birds & 0 & 0 & 0 & 23.0 \\
\hline Mammals & 0 & 0.7 & 2.1 & 12.5 \\
\hline Levin's index & 0.113 & 0.165 & 0.186 & 0.674 \\
\hline $\begin{array}{l}\text { Shannon-Wiener } \\
\text { index }\end{array}$ & 0.639 & 1.01 & 1.19 & 1.67 \\
\hline
\end{tabular}




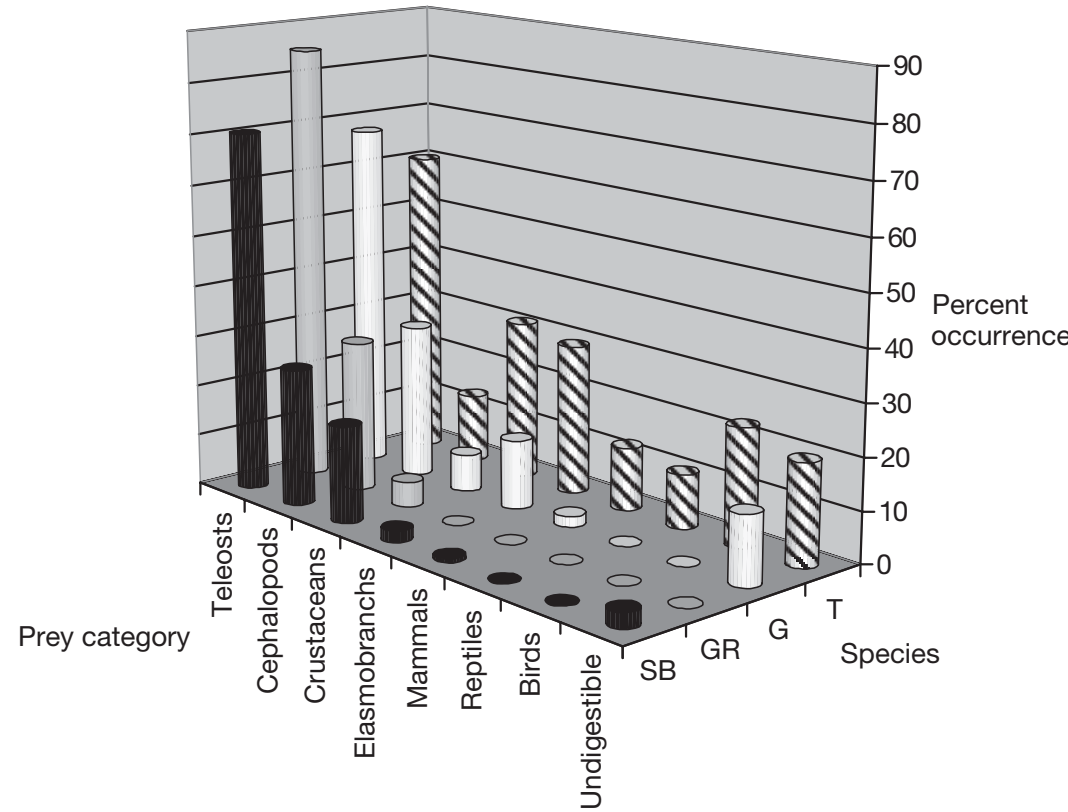

Fig. 6. Carcharhinus plumbeus, C. galapagensis, C. amblyrhynchos, Galeorcerdo cuvier. Diet comparison of major prey taxa between sandbar sharks (SB), gray reef sharks (GR), Galapagos sharks (G), and tiger sharks (T)

and the 2 larger classes (Table 4). For example, the overlap value for largeversus medium-sized sandbar sharks was $C_{\mathrm{H}}=0.92$, compared to $C_{\mathrm{H}}=0.63$ for large versus small sandbar sharks; for large versus medium tiger sharks $C_{\mathrm{H}}=$ 0.79, compared to $C_{\mathrm{H}}=0.32$ for large versus small tiger sharks; for large versus medium gray reef sharks $C_{\mathrm{H}}=0.71$, compared to $C_{\mathrm{H}}=0.18$ for large versus small gray reef sharks. Within species the highest overlap values occurred most frequently in comparisons between the large and medium size classes. Sandbar sharks exhibited the greatest amount of dietary overlap within species, with a high overlap value $\left(C_{\mathrm{H}}=\right.$ 0.63) even between large and small sandbar sharks.

Among-species comparisons revealed that the diet of tiger sharks was the least similar to that of other species. Particularly, low values of overlap were observed for comparisons between tiger and gray reef sharks. The overlap values

mammals. Teleosts occurred most frequently in stomachs of Galapagos sharks, but these sharks also consumed cephalopods, elasmobranchs, crustaceans, and mammals. Tiger sharks had by far the most diverse diet, with less reliance on teleost prey, but a higher occurrence of crustaceans, elasmobranchs, birds, reptiles, and mammals than for any of the other 3 species of shark. Dietary breadth was greatest for tiger sharks (Table $3, H^{\prime}=1.67, B_{\mathrm{A}}=0.674$ ) and lowest for gray reef sharks $\left(H^{\prime}=0.639, B_{\mathrm{A}}=0.113\right)$. Cumulative prey diversity curves indicated that an asymptote was almost reached for gray reef and tiger sharks, but not for Galapagos sharks (Fig. 7). Hence, we could not completely describe the diet of Galapagos sharks in Hawaii with the available data.

The observed dietary overlap values calculated by the null model for all sharks combined were highly significant $(\mathrm{p}=0)$, with none of the simulated indices (mean $=0.137$, variance $=0.02$ ) being higher than the observed indices (mean $=0.37$, variance $=0.06$ ) . Therefore, the observed overlap was much greater than that expected by chance alone. The observed variance was also higher than all values calculated for the simulated indices, indicating that a wide range of index values was calculated between the shark species. Ontogenetic shifts in diet were observed for each species examined. Within species, simplified Morisita analyses revealed there was generally a high degree of overlap between large and medium size classes, but lower levels of overlap between the smallest size class involving comparisons between these 2 species ranged between 0 and 0.15 (no significant overlap between large tiger sharks and large $\left[C_{\mathrm{H}}=0.11, \mathrm{p}=0.5\right]$ or medium $\left[C_{\mathrm{H}}=0.11, \mathrm{p}=0.75\right]$ gray reef sharks). However, there was significant overlap between large tiger sharks and large Galapagos sharks $\left(C_{\mathrm{H}}=0.6, \mathrm{p}=\right.$

Table 4. Carcharhinus plumbeus, C. galapagensis, C. amblyrhynchos, Galeorcerdo cuvier. Simplified Morisita values, comparing dietary overlap between 4 shark species, for various size classes (ST, MT, LT: small, medium, and large tiger sharks; SG, MG, LG: small, medium, and large Galapagos sharks; SGR, MGR, LGR: small, medium, and large gray reef sharks; SSB, MSB, LSB: small, medium, and large sandbar sharks). For full description of the size classes, see 'Materials and methods'. High dietary overlap is indicated by values $>0.6$ (numbers in bold). Significant overlap in diet existed between sharks $(p=0)$

MT LT SG MG LG SGR MGR LGR SSB MSB LSB

ST $\begin{array}{lllllllllll}0.48 & 0.32 & 0.19 & 0.11 & 0.21 & 0 & 0.09 & 0.12 & 0.09 & 0.14 & 0.17\end{array}$

$\begin{array}{lllllllllll}\text { MT } & \mathbf{0 . 7 9} & 0.25 & 0.11 & 0.57 & 0.03 & 0.15 & 0.13 & 0.11 & 0.21 & 0.33\end{array}$

$\begin{array}{lllllllllll}\text { LT } & \quad & 0.17 & 0.1 & \mathbf{0 . 6 0} & 0.02 & 0.11 & 0.11 & 0.08 & 0.21 & 0.24\end{array}$

$\begin{array}{llllllllll}\text { SG } & 0.46 & 0.41 & 0.18 & 0.37 & \mathbf{0 . 6 6} & 0.44 & 0.41 & 0.43\end{array}$

MG

LG

SGR

MGR

LGR

SSB

MSB $\begin{array}{lllllll}0.46 & 0.07 & 0.35 & 0.58 & 0.38 & 0.5 & 0.49\end{array}$

$\begin{array}{llllll}0.15 & 0.52 & 0.58 & 0.41 & \mathbf{0 . 7 2} & \mathbf{0 . 7 1}\end{array}$

$\begin{array}{lllll}0.26 & 0.18 & 0.14 & 0.29 & 0.22\end{array}$

$\begin{array}{llll}0.71 & 0.54 & 0.80 & 0.75\end{array}$

$\begin{array}{lll}0.58 & 0.75 & 0.76\end{array}$

0.610 .63

0.92 
0.003). The 2 species with the most similar diets were sandbar and gray reef sharks; 4 of the 7 highest overlap values observed were for comparisons between gray reef and sandbar sharks (Table 4). All comparisons between medium or large size classes of these 2 species yielded $C_{\mathrm{H}}$ values $>0.75$ : for medium gray reef versus medium sandbar sharks $C_{\mathrm{H}}=0.80$ (significant overlap, $\mathrm{p}=0.001$ ); for large gray reef versus large sandbar sharks $C_{\mathrm{H}}=0.76(\mathrm{p}=0)$; and for both large gray reef versus medium sandbar and large sandbar versus medium gray reef $C_{\mathrm{H}}=0.75(\mathrm{p}=0.001$ and $\mathrm{p}=$ 0 , respectively). The high overlap between sandbar and gray reef sharks was due to the high proportion of octopus, squid, and teleosts (reef-associated species such as Scaridae, Acanthuridae, and Monocanthidae)
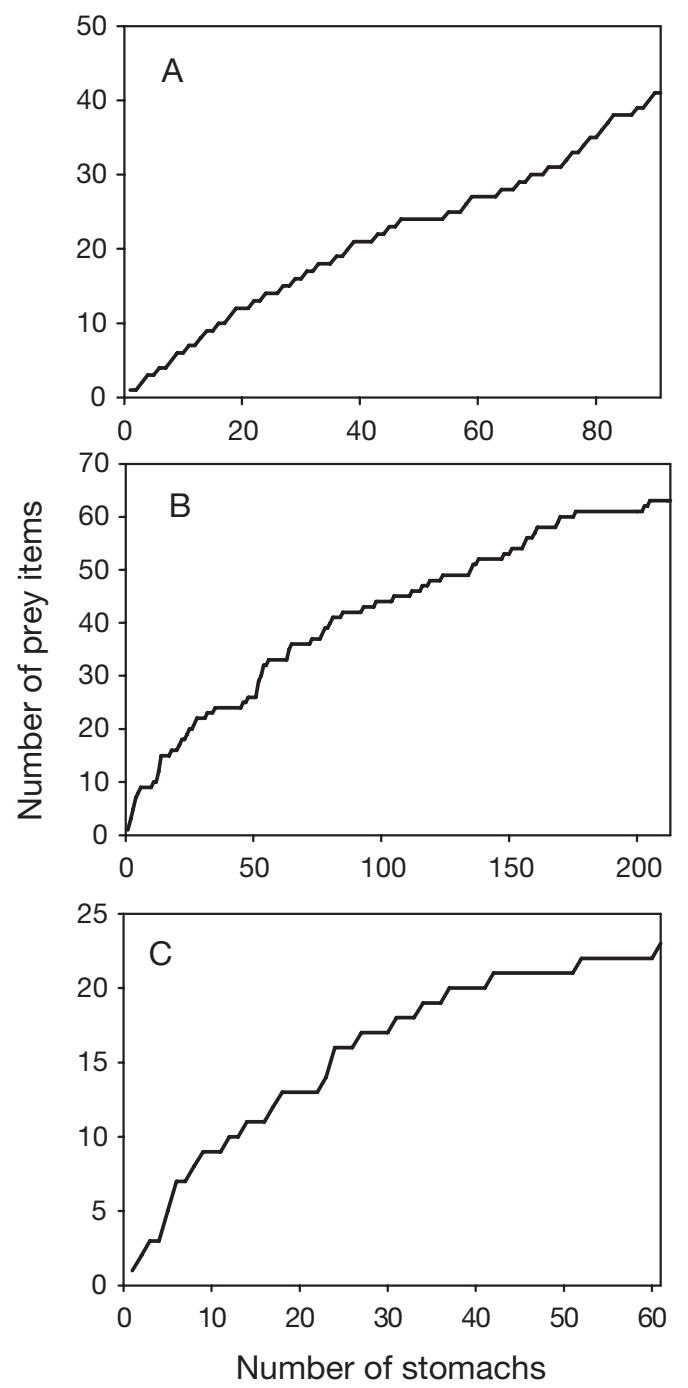

Fig. 7. Carcharhinus galapagensis, C. amblyrhynchos, Galeorcerdo cuvier. Cumulative prey curves for (A) Galapagos sharks, (B) tiger sharks and (C) gray reef sharks. Order of stomachs were randomized 10 times to avoid bias present in the diet. Comparison of the diet of sandbar and gray reef sharks collected at the only location in the archipelago where both species were caught in considerable numbers (Niihau) resulted in low overlap values $\left(C_{\mathrm{H}}=0.14\right)$, although sample sizes were small (32 sandbar sharks, 14 gray reef sharks). High overlap was also calculated between gray reef sharks caught in the MHI with those caught in the NWHI $\left(C_{\mathrm{H}}=0.76\right)$. Overlap values between sandbar and large Galapagos sharks were also high: for large sandbar versus large Galapagos $C_{\mathrm{H}}=0.71(\mathrm{p}=0)$ and for large Galapagos versus medium sandbar sharks $C_{\mathrm{H}}=0.72(\mathrm{p}=0)$.

\section{DISCUSSION}

The dataset upon which this study is based and the shark fishing programs conducted in the Hawaiian Islands on the whole provided intense sampling of shark populations over a short period of time throughout much of the archipelago. These programs captured $>4500$ sharks and yielded information on 13 species of sharks, principally on the 4 species examined in the present study (Carcharhinus plumbeus, C. galapagensis, C. amblyrhynchos, and Galeorcerdo cuvier). As such, this information represents one of the most extensive databases assembled over a relatively large geographical area, particularly for an island chain or coral reef environment, and provides a uniquely large amount of information to investigate ecological interactions among species of sharks.

Ecological theory predicts that there is some degree of resource partitioning among the species of sharks examined in this study. Separation among these species may occur on any number of levels, including spatial or dietary. The dataset examined in our study is supportive of this theoretical prediction about resource partitioning, on the basis of both geographical segregation and differences in diet among sharks in Hawaiian waters.

\section{Distributional patterns of sharks in Hawaii-depth}

Depth-of-capture data suggest that the 4 most abundant species of coastal sharks largely overlap in their vertical range. Capture depths for these species ranged from near the surface to depths of several hundred meters. The majority of sharks were caught shallower than $100 \mathrm{~m}$, although fishing effort was also much greater at shallower depths. Gray reef sharks appeared to have the shallowest distribution, with an average depth of capture for all groups of $<40 \mathrm{~m}$. Gray reef sharks have shallow distributions in other locations as well; those manually tracked in the Marshall Islands generally remained at depths shallower than 
$60 \mathrm{~m}$ (McKibben \& Nelson 1986). The majority of sandbar sharks were captured between 60 and $90 \mathrm{~m}$. Preliminary data from an archival satellite transmitter applied to a sandbar shark off Oahu indicated diel changes in depth, with movements between 0 and $120 \mathrm{~m}$ (K. Holland unpubl. data). Although Galapagos sharks were captured in deep water and these sharks may have a relatively deep range in the $\mathrm{MHI}$, most were captured at depths of $<80 \mathrm{~m}$, and these sharks were very common in shallower waters of the NWHI. Tiger sharks appear to occur at a wide range of depths, although they were most frequently captured in relatively shallow water $(<60 \mathrm{~m})$. Acoustic telemetry studies have demonstrated that tiger sharks predominately occur within $80 \mathrm{~m}$ of the surface, although they may make occasional, short-duration dives into deep water and may range far from shore (Polovina \& Lau 1993, Holland et al. 1999). Segregation between adult male and female sharks has been observed for many species (Springer 1967). Although there was some evidence of depth segregation among mature males and females, and juvenile sharks (all species except for tiger), overlap was still high for sharks caught in Hawaiian waters. Some caution must be used when inferring vertical distribution of fish from long-line capture data, as studies have shown that bait can be taken while long-lines are sinking or rising (e.g. Boggs 1992). However, the data we present appear to agree with results from telemetry studies and, at the very least, provide a framework for additional studies on vertical habitat use of sharks in Hawaii.

\section{Distributional patterns of sharks in Hawaii-geographical}

The catch data examined in this study demonstrated marked differences in the patterns of distribution for the 4 most abundant coastal shark species within the Hawaiian Islands and suggest that there was an inverse relationship between the abundance of sandbar sharks and the abundance of the other 3 species in the MHI. Although the combination of limited fishing effort in the NWHI compared to the MHI and the removal of hundreds of sharks from the MHI population during successive fishing circuits hinder direct comparison of CPUE for the MHI and NWHI, the abundant CPUE data illustrate clear patterns in the geographical range and relative abundance of each of these species throughout the Hawaiian Archipelago.

Although tiger sharks were caught throughout the archipelago, their CPUE was higher in the NWHI than in the MHI. CPUE for tiger sharks throughout the MHI, where the fishing effort was greatest, was both temporally and spatially variable (see Wetherbee et al. 1994).
Galapagos sharks were not captured in large numbers in the MHI, but were consistently captured at specific locations throughout the MHI, with highest CPUE observed at Niihau. Like tiger sharks, Galapagos sharks were most abundant in the NWHI, where CPUE values were highest and where they were the most frequently captured species. This trend of increasing abundances of large predatory sharks from south to north has also been observed in diver-based surveys across the archipelago. Despite methodological problems with in situ quantification of large apex-predatory fishes (coastal sharks and jacks), Friedlander \& DeMartini (2002) found apex predators to be much more abundant in the NWHI than in the MHI, comprising up to nearly $54 \%$ of the fish biomass in the NWHI.

Distributional patterns for sandbar and gray reef sharks were less continuous than those of tiger and Galapagos sharks. The most abundant coastal shark in all fishing in the MHI was the sandbar shark, which had relatively high CPUE values throughout the MHI, but was rare in the NWHI. In contrast, gray reef sharks were only sporadically found within the MHI, but were one of the most abundant sharks throughout the NWHI. The only areas where $>10$ gray reef sharks were caught within the MHI were Molokini and Niihau. Niihau is the northernmost island in the MHI and Molokini is a small crater thought to have been a nursery area for gray reef sharks (Wass 1971, Wetherbee et al. 1997). During a shark fishing program currently in progress off the east shore of Oahu, no gray reef sharks have been captured over the past 2 yr (R. D. Grubbs pers. comm.), suggesting that this species is still uncommon in the MHI.

The general pattern of wide spread and overlapping distribution for the 4 most common species of shark indicates that at least 3 of these species co-occur throughout most of the Hawaiian Islands. Large numbers of tiger, Galapagos, and sandbar sharks coexist in the MHI, and large numbers of tiger, Galapagos, and gray reef sharks coexist in the NWHI.

The observation of distinctly different distributional patterns among the 4 species of sharks examined in this study raises the question: What factors are responsible for the observed distributions? Analyses of the diet of the 4 species of sharks investigated also illustrate patterns in their feeding habits and indicate that there is some degree of resource partitioning and possibly competitive interactions among these species. There is also evidence that distributional patterns of these sharks are reflective of differential habitat selection among species and among segments of the population of individual species. The data in our study also indicate that predation among sharks may also influence the patterns of distribution observed for the sharks examined. 


\section{Distributional patterns - resource partitioning}

Cumulative prey curves show that our data provide a good description of the diet of gray reef and tiger sharks, while additional stomachs would be needed to completely describe the diets of Galapagos and sandbar sharks (McElroy et al. 2006, present paper). Indices of dietary overlap between species were generally low, with the exception of comparisons between the diet of gray reef sharks and sandbar sharks, sandbar and large Galapagos sharks, and large Galapagos and large tiger sharks. The 4 highest values of dietary overlap observed for interspecific comparisons involved sandbar and gray reef sharks, indicating that the diet of these 2 species are more similar than the diets of any other 2 species. The high dietary overlap was due to both species feeding predominantly on crustaceans, octopus, squid, and mostly reef-associated teleosts (e.g. Scaridae, Acanthuridae, Monocanthidae). While perceived dietary overlap between these species may be elevated by the relatively low taxonomic resolution in dietary analysis, other evidence also suggests a high level of dietary overlap. For example, in coastal reef environments in Hawaii, there are only 2 relatively large species of octopus (Hoover 1999). Additionally, the majority of fishes in the families Scaridae and Acanthuridae are herbivorous and thought to be diurnal (Randall 1996). Hence, at the very least, gray reef and sandbar sharks feed on animals from the same feeding guilds and feed upon ecologically similar groups. Furthermore, at Niihau, the only location where large numbers of gray reef and sandbar sharks co-occur, dietary overlap was very low, although sample sizes available for this comparison were also low. A high degree of dietary overlap was also observed between large Galapagos sharks and adult sandbar sharks, and these 2 species also showed an inverse distributional relationship. Therefore, analyses of stomach contents of sharks collected in the Hawaiian Islands support the theoretical prediction that the diet of co-occurring species of sharks differ and that sharks with very similar diets do not co-occur. The diets of sandbar and gray reef sharks demonstrate a high degree of similarity, but these 2 species are, for the most part, allopatric.

An alternative or contributive explanation for observed patterns of shark distribution is species-specific habitat preference. There are a number of habitatrelated differences between the mountainous, humaninhabited, relatively younger MHI and the low-relief, uninhabited, older NWHI. These differences include the amount of freshwater runoff, water turbidity, water temperature, and development of corals and ecosystem structure, fishing pressure, and associated influence on prey abundance. The shark catch data exam- ined in our study as well as in recent surveys indicate that there are differences in the distribution and abundance of individual species of shark within the MHI and the NWHI. The MHI and NWHI may represent very different biotic environments as well. For example, Lowe et al. (1996) found that there were major differences between the diet of tiger sharks in the MHI and tiger sharks in the NWHI.

Wass (1971) suggested that sandbar sharks prefer areas with weak currents and a level sea floor comprising a substratum of fine rubble, sand, or mud. Gray reef sharks are thought to prefer clearer water and more high-relief, hard substratum (Wass 1971, Johnson 1978, Wetherbee et al. 1997). Habitat preferred by sandbar sharks may be more prevalent in the MHI, whereas habitat most suitable for gray reef sharks may be more common in the NWHI. In Tahiti (where sandbar sharks are absent), gray reef sharks are reportedly more common near small, low-relief islands compared with large, high-relief islands with larger human populations (Johnson 1978). Therefore, the allopatric distributions of sandbar and gray reef sharks in the Hawaiian Islands may reflect resource partitioning between these 2 species on the basis of habitat rather than prey.

\section{Distributional patterns - predation among sharks}

The data examined in this study also reveal evidence of predator-prey interactions among sharks in Hawaii. The presence of elasmobranchs, including sandbar sharks, in the diet of tiger sharks, as well as the inverse relationship in CPUE of these 2 species indicates that tiger shark predation on sandbar sharks may influence the distribution of sandbar sharks. Changes in the species composition of sharks caught in successive fishing circuits around the island of Oahu from 1967 to 1969 may also provide evidence of these predator-prey relationships. During this time period there was an increase in the CPUE of sandbar sharks, with a concurrent decrease in the CPUE of tiger sharks. However, there are several caveats in this interpretation, as the average size of tiger sharks increased during this period and the bait used was changed toward the end of the consecutive fishing circuits around Oahu (Wetherbee et al. 1994). There are other reports of a proliferation of smaller elasmobranchs following the removal of larger predators. Van der Elst (1979) reported an increase in small sharks in association with a shark meshing program for large sharks in Natal, South Africa, and an increase in the abundance of smaller skate species (Raja spp.) in the NE Atlantic was attributed to competitive release caused by fishing removal of larger species (Dulvy et al. 2000). 


\section{CONCLUSIONS}

For competition to exist, dietary and spatial overlap must occur (or have occurred) and resources must be limiting (Colwell \& Futuyma 1971). It is difficult to assess the degree to which food resources for gray reef and sandbar sharks are, or were, in short supply, and dietary overlap between these species most likely would have been lower with identification of prey to a lower taxonomic level, due to their occupying distinctly different habitats. Studies with coral reef fishes have shown that dietary overlap may be an artifact of low taxonomic resolution when identifying prey items, with estimates of overlap decreasing as taxonomic resolution is increased (Longnecker 2001). Based on the apparent similarity between the diets of gray reef and sandbar sharks, their disparate distributions are in agreement with the competitive exclusion principle that complete competitors cannot coexist (Krebs 2001). Wiens (1989) offered criteria for establishing the occurrence of interspecific competition, including observation of distributional patterns consistent with predictions, species overlap in resource use, and intraspecific competition. Our study provides evidence for these criteria, although data are insufficient for providing what Wiens (1989) termed 'convincing' evidence of competition.

Additional data or experimental work would be necessary to further examine the role of competition and other ecological interactions operating in the assemblage of coastal sharks in Hawaii. Typical experimental methods used to examine competition (such as removal of 1 species) are not practical for large, mobile elasmobranchs. However, several features of the distributional patterns and feeding niches of gray reef and sandbar sharks may be examined following this line of reasoning. Further investigation of behavioral differences (space utilization, activity patterns, habitat use) of sandbar and gray reef sharks both at locations where they co-occur and at locations where the 'competitor' is absent would also contribute to a greater understanding of competitive interactions between these species. Regardless of whether the allopatric distributional patterns observed for gray reef and sandbar sharks are related to competition, or are shaped by habitat preferences or other factors, resource competition between these 2 species is minimized by the limited degree of overlap of their ranges within the Hawaiian Islands.

Even though the data used in this study are $>35 \mathrm{yr}$ old, they provide a comprehensive database upon which to infer patterns of distribution and the factors that influence these patterns for the 4 species of coastal shark in the Hawaiian Islands. These species coexist spatially, while the generally low values of dietary overlap indicate ecological separation on the basis of feeding niches. The disparate distribution of gray reef and sandbar sharks in conjunction with a high degree of dietary overlap is suggestive of competitive interactions between these 2 species.

Acknowledgements. This study would not have been possible without the tireless efforts of A. L. Tester and the other participants in completion of the Hawaii Cooperative Shark Research and Control Program and the collection of the data that form the basis for this study. Original funding for the Hawaii Cooperative Shark Research and Control Program was provided by NSF GB-6139, the Oceanic Institute, and the State of Hawaii. J. Stimson and the Zoology Department at the University of Hawaii maintained the original data sheets for many years prior to providing access for use in this study. We thank M. DeCrosta, J. Parrish, and others for collection of data from the NWHI. We also thank K. Holland for satellite tag data from a sandbar shark, R. Grubbs for assistance with dietary overlap analysis, and C. Meyer for help with figures. Finally, we thank the 3 anonymous reviewers whose comments greatly improved the manuscript.

\section{LITERATURE CITED}

Bethea DM, Buckel JA, Carlson JK (2004) Foraging ecology of the early life stages of four sympatric shark species. Mar Ecol Prog Ser 268:245-264

Boggs CH (1992) Depth, capture time, and hooked longevity of longline-caught pelagic fish: timing bites of fish with chips. Fish Bull 90(4):642-658

Cartamil DP, Vaudo JJ, Lowe CG, Wetherbee BM, Holland KN (2003) Diel movement patterns of the Hawaiian stingray, Dasyatis lata: implications for ecological interactions between sympatric elasmobranch species. Mar Biol 142(5):841-847

Colwell RK, Futuyma DJ (1971) On the measurement of niche breadth and overlap. Ecology 52(4):567-576

Connor EF, Simberloff D (1979) The assembly of species communities: Chance or competition? Ecology 60:1132-1140

Cortés E (1997) A critical review of methods of studying fish feeding based on analysis of stomach contents: application to elasmobranch fishes. Can J Fish Aquat Sci 54:726-738

Cortés E (1999) Standardized diet compositions and trophic levels of sharks. ICES J Mar Sci 56:707-717

Crow GL, Lowe CG, Wetherbee BM (1996) Shark records from longline fishing programs in Hawaii with comments on Pacific Ocean distributions. Pac Sci 50(4):382-392

DeCrosta MA, Taylor LR, Parrish JD (1984) Age determination, growth and energetics of three species of carcharinid sharks in Hawaii. In: Grigg RW, Tanoue KY (eds) Proc 2nd Symp Res Invest NWHI, Vol. 2. UNIHI-SEA-GRANT-MR84-01, University of Hawaii Sea Grant, Honolulu, HI, p 75-95

Dulvy NK, Metcalfe JD, Glanville J, Pawson MG, Reynolds JD (2000) Fishery stability, local extinctions, and shifts in community structure in skates. Conserv Biol 14(1): 283-293

Ellis JR, Pawson MG, Shackley SE (1996) The comparative feeding ecology of six species of shark and four species of ray (Elasmobranchii) in the North-East Atlantic. J Mar Biol Assoc UK 76:89-106

Ferry LA, Cailliet GM (1996) Sample size and data analysis: Are we characterizing and comparing diet properly? In: Mackinlay D, Shearer K (eds) Feeding ecology and nutri- 
tion in fish. Proc Symp Feeding Ecology and Nutrition in Fish, Int Congr Biol Fish. American Fisheries Society, San Francisco, CA, p 71-80

Friedlander AM, DeMartini EE (2002) Contrast in density, size and biomass of reef fishes between the northwestern and the main Hawaiian Islands: the effect of fishing down apex predators. Mar Ecol Prog Ser 230:253-264

Gotelli NJ, Entsminger GL (2001) EcoSim: null models software for ecology, Ver. 7.0. Acquired Intelligence and Kesey-Bear. Available at http://homepages.together.net/ gentsmin/ecosim.htm

Heithaus MR (2004) Predator-prey interactions. In: Carrier JC, Musick JA, Heithaus MR (eds) Biology of sharks and their relatives. CRC Press, Boca Raton, FL

Hixon MA (1980) Competitive interactions between California reef fishes of the genus Embiotoca. Ecology 61(4): 918-931

Holland KN, Wetherbee BM, Lowe CG, Meyer CG (1999) Movements of tiger sharks (Galeorcerdo cuvier) in coastal Hawaiian waters. Mar Biol 134:665-673

Hoover JP (1999) Hawaii sea creatures, a guide to Hawaii's marine invertebrates. Mutual Publishing, Honolulu, HI

Jansen PA, Slettvold H, Finstad AG, Langeland A (2002) Niche segregation between Arctic char (Salvelinus alpinus) and brown trout (Salmo trutta): an experimental study of mechanisms. Can J Fish Aquat Sci 59:6-11

Johnson RH (1978) Sharks of tropical and temperate seas. Les Editions du Pacifique, Singapore

Krebs CJ (1999) Ecological methodology, Ver. 5.1. Department of Zoology, University of British Columbia, Vancouver. Available at http://nhsbig.inhs.uiuc.edu/wes/krebs. html

Krebs CJ (2001) Ecology. Benjamin Cummings, San Francisco, CA

Langeland A, L'abee-Lund JH, Jonsson B, Jonsson N (1991) Resource partitioning and niche shift in Arctic charr, Salvelinus alpinus, and brown trout, Salmo trutta. J Anim Ecol 60(3):895-912

Langton RS (1982) Diet overlap between the Atlantic cod, Gadus morhua, silver hake, Merluccius bilinearis and fifteen other northwest Atlantic finfish. Fish Bull 80:745-759

Longnecker KR (2001) The role of food in the community structure of reef fishes. PhD dissertation, University of Hawaii at Manoa, Honolulu, HI

Lowe CG, Wetherbee BM, Crow GL, Tester AL (1996) Ontogenetic dietary shifts and feeding behavior of the tiger shark, Galeocerdo cuvier, in Hawaiian waters. Environ Biol Fish 47:203-211

Editorial responsibility: Kenneth Sherman (Contributing Editor), Narragansett, Rhode Island, USA
Lucas Z, Stobo WT (2000) Shark inflicted mortality on a population of harbour seals (Phoca vitulina) at Sable Island, Nova Scotia. J Zool 252:405-414

McElroy DW, Wetherbee BM, Mostello CS, Lowe CG, Crow GL, Wass RC (2006) Food habits and ontogenetic changes in the diet of the sandbar shark (Carcharhinus plumbeus) in Hawaii. Environ Biol Fish 76(1):81-92

McKibben JN, Nelson DR (1986) Patterns of movement and grouping of gray reef sharks, Carcharhinus amblyrhynchos, at Enewetak, Marshall Islands. Bull Mar Sci 38:68-88

Pianka ER (1973) The structure of lizard communities. Annu Rev Ecol Syst 4:53-74

Polovina JJ, Lau B (1993) Temporal and spatial distribution of catches of tiger sharks, Galeocerdo cuvier, in the Pacific longline fishery around the Hawaiian Islands. Mar Fish Rev 55(3):1-3

Randall JE (1996) Shore fishes of Hawaii. Natural World Press, Vida, OR

Springer S (1967) Social organization of shark populations. In: Gilbert PW, Mathewson RF, Rall DP (eds) Sharks, skates and rays. Johns Hopkins Press, Baltimore, MD

Van der Elst RP (1979) A proliferation of small sharks in the shore-based Natal sport fishery. Environ Biol Fish 4: 349-362

Wass RC (1971) A comparative study of the life history, distribution, and ecology of the sandbar shark and gray reef shark in Hawaii. PhD dissertation, University of Hawaii, Honolulu, HI

Wetherbee BM, Lowe CG, Crow GL (1994) A review of shark control in Hawaii with recommendations for future research. Pac Sci 48(2):95-115

Wetherbee BM, Crow GL, Lowe CG (1996) Biology of the Galapagos shark, Carcharhinus galapagensis, in Hawaii. Environ Biol Fish 45:299-310

Wetherbee BM, Crow GL, Lowe CG (1997) Distribution, reproduction and diet of the gray reef shark, Carcharhinus amblyrhynchos, in Hawaii. Mar Ecol Prog Ser 151: 181-189

White WT, Platell ME, Potter IC (2004) Comparisons between the diets of four abundant species of elasmobranchs in a subtropical embayment: implications for resource partitioning. Mar Biol 144:439-448

Wiens JA (1989) The ecology of bird communities, Vol 2. Processes and variations. Cambridge University Press, Cambridge

Zaret TM, Rand AS (1971) Competition in tropical stream fishes: support for the competitive exclusion principle. Ecology 52(2):336-342

Submitted: August 15, 2005; Accepted: February 14, 2006 Proofs received from author(s): July 28, 2006 